\title{
Impact of Cr Substitution on Structural, Magnetic, Electric and Impedance Study of Mn-Ni-Zn Ferrites
}

\author{
Shanzida Haque ${ }^{1}$, Sajal Chandra Mazumdar ${ }^{*}$, Mohammed Nazrul Islam Khan², \\ Mithun Kumar Das ${ }^{1}$
}

${ }^{1}$ Department of Physics, Comilla University, Cumilla, Bangladesh

${ }^{2}$ Material Science Division, Atomic Energy Centre, Dhaka, Bangladesh

Email: *sajalf@yahoo.com

How to cite this paper: Haque, S., Mazumdar, S.C., Khan, M.N.I. and Das, M.K. (2021) Impact of Cr Substitution on Structural, Magnetic, Electric and Impedance Study of Mn-Ni-Zn Ferrites. Materials Sciences and Applications, 12, 121-138. https://doi.org/10.4236/msa.2021.123008

Received: February 9, 2021

Accepted: March 23, 2021

Published: March 26, 2021

Copyright $\odot 2021$ by author(s) and Scientific Research Publishing Inc. This work is licensed under the Creative Commons Attribution International License (CC BY 4.0).

http://creativecommons.org/licenses/by/4.0/

\begin{abstract}
A series of $\mathrm{Cr}^{3+}$-substituted $\mathrm{Mn}-\mathrm{Ni}-\mathrm{Zn}$ ferrites; $\mathrm{Mn}_{0.5} \mathrm{Ni}_{0.1} \mathrm{Zn}_{0.4} \mathrm{Fe}_{2-x} \mathrm{Cr}_{x} \mathrm{O}_{4}(x=$ $0.0-0.4$ in a step of 0.1 ) were prepared by traditional solid-state reaction route. The structural, magnetic, dielectric properties and impedance spectroscopy of these compositions were studied. Phase identification and lattice constant $\left(a_{0}\right)$ determination were carried out by X-ray diffraction (XRD). The XRD patterns established the fabrication of a single-phase spinel structure. The FESEM micrographs exposed that the average grain size $(\bar{D})$ increased slightly with chromium (Cr) substitution and then decreased for a higher concentration of chromium in the composition. The real part of initial permeability $\left(\mu_{i}^{\prime}\right)$ diminished owing to the enhanced porosity of the compositions with the increase of $\mathrm{Cr}^{3+}$ content in the composition. The highest relative quality factor (RQF) was attained for the samples with $x=0.1$. The magnetic hysteresis was investigated to know the effect of $\mathrm{Cr}^{3+}$ substitution in the composition of the magnetic properties. The decrease of saturation magnetization $\left(M_{s}\right)$ with an enhancement in $\mathrm{Cr}^{3+}$ might be triggered by switching of $\mathrm{Fe}^{3+}$ ions from octahedral to tetrahedral site. The samples with $x=0.1$ exhibited the highest anisotropy constant $(K)$. Curie temperatures of the investigated samples were significantly modified to lower temperatures with the $\mathrm{Cr}^{3+}$ content. The frequency characteristics of dielectric properties and impedance spectroscopy had been investigated. The highest dielectric constant $(\varepsilon)$ and resistivity were observed for $x=0.1$ and $x=0.2$ samples. The complex impedance spectra analysis reveals in-depth information about the conduction mechanism, microstructure, and orientation of the grains in the samples.
\end{abstract}

\section{Keywords}

X-Ray Diffraction, Permeability, Dielectric Property, Curie Temperature, 
Impedance Spectroscopy

\section{Introduction}

During the last few decades, ferrites are materials of great interest owing to their notable magnetoelectric properties. According to the structure, they have tetrahedral A-site and octahedral B-sites in the $\mathrm{AB}_{2} \mathrm{O}_{4}$ crystal lattice. These materials exhibit diverse magnetic and electrical properties subject to their cation distribution of the chemical compositions. Numerous cations could be located on the A-site and B-sites to modify their magnetic properties [1] [2] [3] [4]. Sivakumar et al. [1] studied the effect of milling, grain size, frequency, and temperature on the dielectric properties of nanocrystalline Ni-Zn ferrites. They found an unusual rise in dielectric loss with milling resulting from increased electrical conductivity due to oxygen vacancies introduced upon milling. On the other hand, the relaxation frequency was observed to decrease with milling due to increased interaction between charge carriers. Hossain et al. [2] observed that with the increase in $\mathrm{Zn}$ content in $\mathrm{Ni}$-ferrite the Curie temperature $\left(T_{c}\right)$, resistivity, and the activation energy dropped off whereas the magnetization, initial permeability, and the relative quality factor $(\mathrm{Q})$ increased. A Hopkinson peak was obtained near $T_{c}$ in the real part of the initial permeability vs. temperature curves. Chukalkin et al. [5] [6] and Mahmud et al. [6] observed the effect of Zn substitution on the magnetic properties Ni-Zn ferrites. Local angular structures of spin were evident for $x=0.45$ with effective sizes of $1-10 \mathrm{~nm}$ [5] [6]. Rezlescu et al. studied the effect of divalent ions [7] and rare earth ions [8] on the structural, magnetic and electric properties of $\mathrm{Ni}-\mathrm{Zn}$ ferrites.

From the functional viewpoint, $\mathrm{Mn}-\mathrm{Zn}$ along with $\mathrm{Ni}-\mathrm{Zn}$ ferrites epitomizes the most significant types. These are utilized in various ferrite devices for instance converters, inductor cores, electromagnetic wave absorbers, recording heads, etc. Mn-Zn ferrites own high $\mu_{i}^{\prime}$ and magnetization but these are not appropriate for magnetic uses at higher frequencies owing to their high electrical conductivity and excessive power losses. In contrast, $\mathrm{Ni}-\mathrm{Zn}$ ferrites have giant resistivity, small-dielectric loss $\left(\tan \delta_{E}\right)$, and high Curie temperature $\left(T_{C}\right)$, but they have somewhat minimal $\mu_{i}^{\prime}$ at higher frequencies. Several authors considered the mixture of these two ferrites to obtain encouraging magnetic characteristics with moderate losses particularly in the excessive frequency range [9] [10] [11] [12]. In earlier studies, the magnetic and electrical effects of this sort of mixture were evaluated [12] [13]. The composition $\mathrm{Mn}_{0.5} \mathrm{Ni}_{0.1} \mathrm{Zn}_{0.4} \mathrm{Fe}_{2} \mathrm{O}_{4}$ was found to possess the optimum magnetic characteristics for auspicious functions [12] [14] [15]. Preferential occupation of $\mathrm{Cr}^{3+}$ ions by octahedral sites in Ni-Zn ferrites replaces $\mathrm{Fe}^{3+}$ ions limiting $\mathrm{Fe}^{2+}-\mathrm{Fe}^{3+}$ hoping conduction and increases resistivity. Accordingly, in the present work, we are interested to deal with the enhancement of the electrical properties of the optimum composition $\mathrm{Mn}_{0.5} \mathrm{Ni}_{0.1} \mathrm{Zn}_{0.4} \mathrm{Fe}_{2} \mathrm{O}_{4}$ 
by substituting $\mathrm{Cr}^{3+}$ ions in octahedral B-site.

\section{Materials and Methods}

The $\mathrm{Mn}_{0.5} \mathrm{Ni}_{0.1} \mathrm{Zn}_{0.4} \mathrm{Fe}_{2-x} \mathrm{Cr}_{x} \mathrm{O}_{4}$ (where $x=0.0$ - 0.4) samples were fabricated by standard solid-state reaction technique. High purity (99.9\%) crushes of $\mathrm{MnCO}_{3}$, $\mathrm{NiO}, \mathrm{ZnO}, \mathrm{Cr}_{2} \mathrm{O}_{3}$, and $\mathrm{Fe}_{2} \mathrm{O}_{3}$ were utilized as untreated substances for the synthesis of $\mathrm{Mn}_{0.5} \mathrm{Ni}_{0.1} \mathrm{Zn}_{0.4} \mathrm{Fe}_{2-x} \mathrm{Cr}_{x} \mathrm{O}_{4}$ compositions. The constituents in requisite stoichiometric amounts were mixed mechanically by hand milling in acetone media using a ceramic mortar for 6 hours and calcined in ambient air at $700^{\circ} \mathrm{C}$ for 3 hours. Afterward, the calcined powders were shaped into pellets and rings by a hydraulic press. After that, the samples were sintered at $1100^{\circ} \mathrm{C}, 1150^{\circ} \mathrm{C}$ and $1200^{\circ} \mathrm{C}$ for 3 hours. The temperature variation for sintering was $5^{\circ} \mathrm{C} / \mathrm{min}$ during heating and $10^{\circ} \mathrm{C} / \mathrm{min}$ during cooling. The compositions sintered at $1150^{\circ} \mathrm{C}$ were reserved for characterization based on optimum density. Some of these samples were polished for complex initial permeability and electrical characterization.

The XRD of the samples was performed using PHILIPS PW 3040 X'pert PRO $\mathrm{X}$-ray diffractometer. The Nelson-Riley process was utilized for determining the precise $a_{0}$ of the samples. The Nelson-Riley (N-R) function $F(\theta)$ is specified by

$$
F(\theta)=\frac{1}{2}\left(\frac{\cos ^{2} \theta}{\sin \theta}+\frac{\cos ^{2} \theta}{\theta}\right)
$$

where $\theta$ demonstrates the Bragg angle. The values of $a_{0}$ for all the peaks of a sample were plotted as a function of $F(\theta)$. After that utilizing the least square fitting method precise lattice constants were found out. The point where the least square fitting straight line meets the y-axis (i.e. at $F(\theta)=0$ ) is the real $a_{0}$ of the sample.

Bulk density $\left(\rho_{B}\right)$ of all the samples was measured by the formulae [16]:

$$
\rho_{B}=\frac{m}{\pi r^{2} t}
$$

where $m, r$, and $t$ represent the mass, radius, and thickness of the pellet or ring, individually. The X-ray density $\left(\rho_{x}\right)$ was computed applying the following expression:

$$
\rho_{x}=\frac{n M}{N_{A} V}
$$

where $n, M, N_{A}$, and $V$ reflect the number of atoms in a unit cell, the molar mass, Avogadro's number, and unit cell volume, separately. The porosity $(P)$ was determined from the expression

$$
P(\%)=\frac{\rho_{x}-\rho_{B}}{\rho_{x}} \times 100 \%
$$

The electromagnetic properties were characterized at ambient temperature as a function of frequency using WAYNE KERR 6500B Impedance Analyzer. The 
$\mu_{i}^{\prime}$ was calculated with the following relations [17]:

$$
\begin{aligned}
\mu_{i}^{\prime} & =\frac{L_{s}}{L_{0}} \\
\text { and } L_{0} & =\frac{\mu_{0} N^{2} S}{\pi \bar{d}}
\end{aligned}
$$

where, $L_{s}$ is the self-inductance of the sample core and $L_{0}$ is the winding coil inductance in absence of sample core, $N$ is the number of windings of the coil $(N=$ 5), $S$ is the cross-sectional area of the ring-shaped sample, $S=d \times h$, where, $d=\frac{d_{2}-d_{1}}{2}$ and $\bar{d}=\frac{d_{1}+d_{2}}{2}$ is the mean diameter of the ring-shaped sample. The RQF was settled from the ratio, $\frac{\mu_{i}^{\prime}}{\tan \delta_{M}}$. The $T_{C}$ of the compositions was computed from the temperature-controlled $\mu_{i}^{\prime}$.

For dielectric measurements, disk-shaped samples have been painted with silver paste on both sides for better electrical contact. The $\varepsilon^{\prime}$ was estimated using the given formula [3]:

$$
\begin{aligned}
\varepsilon^{\prime} & =\frac{C}{C_{0}} \\
\text { and } \varepsilon^{\prime \prime} & =\varepsilon^{\prime} \tan \delta_{E}
\end{aligned}
$$

where $C$ is the capacitance of the dielectric materials and $C_{0}=\frac{\varepsilon_{0} A}{t}$ is resulting geometrically. Here $C_{0}$ is the capacitance of the capacitor in the absence of dielectric specimens, $\varepsilon_{0}$ is the permittivity of free space $\left(\varepsilon_{0}=8.85 \times 10^{-12} \mathrm{Fm}^{-1}\right), t$ is the thickness and $A\left(=\pi r^{2}\right)$ is the cross-sectional area of the sample painted with silver paste.

Dielectric relaxation and conduction processes were accomplished in the complex modulus $\left(M^{\prime}\right)$ spectra. The real $(M)$ and imaginary $\left(M^{\prime \prime}\right)$ segments of electric modulus were picked up from the dielectric data from the relations:

$$
\begin{gathered}
M^{\prime}=\frac{\varepsilon^{\prime}}{\varepsilon^{\prime 2}+\varepsilon^{\prime \prime 2}} \\
\text { and } M^{\prime \prime}=\frac{\varepsilon^{\prime \prime}}{\varepsilon^{\prime 2}+\varepsilon^{\prime \prime 2}}
\end{gathered}
$$

\section{Results and Discussion}

\subsection{X-Ray Diffraction, Lattice Constant, Density, and Porosity}

XRD patterns for the samples $\mathrm{Mn}_{0.5} \mathrm{Ni}_{0.1} \mathrm{Zn}_{0.4} \mathrm{Fe}_{2-x} \mathrm{Cr}_{x} \mathrm{O}_{4}(x=0.0,0.1,0.2,0.3,0.4)$ sintered at $1150^{\circ} \mathrm{C}$ for 3 hours are represented in Figure 1. The peaks in the XRD patterns disclose the single-phase spinel structure. The position of the XRD peaks is in good concurrence with other reports [17]. The $a_{0}$, density, and $P$ of the samples are presented in Table 1 . To find the precise value of $a_{0}$, all the values of $a_{0}$ are plotted against the N-R function. The exact value of $a_{0}$ of the sample is that point where the least square fitting straight line cuts the $\mathrm{Y}$-axis. By plotting 


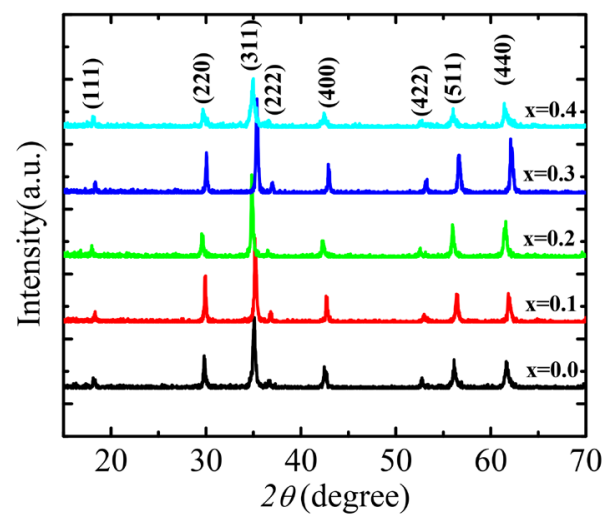

Figure 1. XRD patterns of different $\mathrm{Mn}_{0.5} \mathrm{Ni}_{0.1} \mathrm{Zn}_{0.4} \mathrm{Fe}_{2-x} \mathrm{Cr}_{x} \mathrm{O}_{4}$ ferrites.

Table 1. The $a_{0}, \rho_{B}, \rho_{X}, P$, and $\bar{D}$ of $\mathrm{Mn}_{0.5} \mathrm{Ni}_{0.1} \mathrm{Zn}_{0.4} \mathrm{Fe}_{2-x} \mathrm{Cr}_{X} \mathrm{O}_{4}$ ferrites.

\begin{tabular}{cccccc}
\hline Content $(x)$ & $a_{0}(\AA)$ & $\rho_{B}\left(\mathrm{~g} / \mathrm{cm}^{3}\right)$ & $\rho_{x}\left(\mathrm{~g} / \mathrm{cm}^{3}\right)$ & $P(\%)$ & $\bar{D}(\mu \mathrm{m})$ \\
\hline 0.0 & 8.51 & 4.70 & 5.21 & 9.79 & 0.0861 \\
0.1 & 8.50 & 4.71 & 5.26 & 10.46 & 0.1280 \\
0.2 & 8.52 & 4.63 & 5.29 & 12.48 & 0.1312 \\
0.3 & 8.46 & 4.59 & 5.23 & 12.24 & 0.0846 \\
0.4 & 8.52 & 4.49 & 5.22 & 13.98 & 0.0876
\end{tabular}

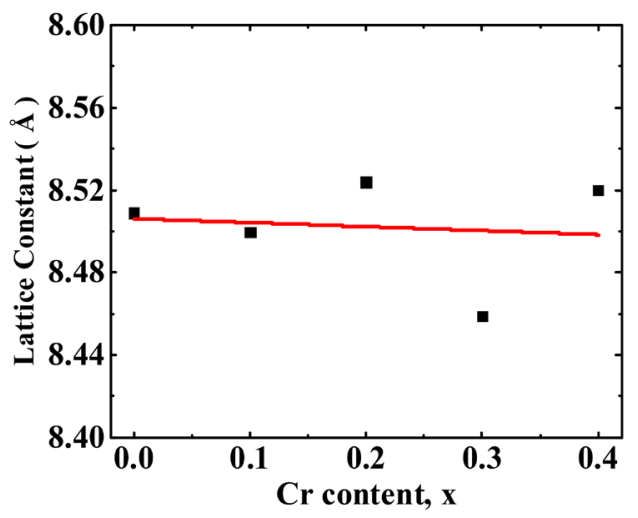

Figure 2. Lattice constant of $\mathrm{Mn}_{0.5} \mathrm{Ni}_{0.1} \mathrm{Zn}_{0.4} \mathrm{Fe}_{2-x} \mathrm{Cr}_{x} \mathrm{O}_{4}$ as a function of $\mathrm{Cr}$ content.

the $a_{0}$ against $\mathrm{Cr}$ content in Figure 2, it appears that the value of the $a_{0}$ drops up to $x=0.3$ with increasing the value of $\mathrm{Cr}$ content showing inconsistency for $x=$ 0.2 and then rises with $\mathrm{Cr}$ content. This drop of the $\mathrm{a}_{0}$ with increasing $\mathrm{Cr}$ content establishes the fact that the $a_{0}$ is proportional to the rise of the ionic radius as the ionic radius of $\mathrm{Cr}^{3+}(0.64 \AA)$ is less than that of $\mathrm{Fe}^{3+}(0.67 \AA)$ [18]. After $x=0.3$, the $a_{0}$ rises with increasing $\mathrm{Cr}$ content. The rise in the $a_{0}$ for a higher concentration of Cr was also observed by Li et al. [19] The rise in the $a_{0}$ for a higher concentration of $\mathrm{Cr}$ may be due to the fact that instead of trivalent the divalent $\mathrm{Cr}$ ion substitutes $\mathrm{Fe}^{2+}$ in the A-site which results in the increase of lattice constant as the lattice constant of $\mathrm{Cr}^{2+}$ is larger than that of $\mathrm{Fe}^{2+}$ [19]. Another possible reason is: the oxides of $\mathrm{Cr}$ reside at the grain boundary (as seen from the micro- 
graphs in section 3.2) thereby obstructing the grain growth and exerts a stress on the unit cell. To compensate for the stress exerted by the grain boundary, the $a_{0}$ rises for higher $\mathrm{Cr}^{3+}$ concentration. The inconsistency from the declining trend for $x=0.2$ may be caused by the inhomogeneous diffusion of $\mathrm{Cr}^{3+}$ in the lattice.

The alteration of $\rho_{B}$ and X-ray density $\left(\rho_{x}\right)$ of $\mathrm{Mn}_{0.5} \mathrm{Ni}_{0.1} \mathrm{Zn}_{0.4} \mathrm{Fe}_{2-x} \mathrm{Cr}_{x} \mathrm{O}_{4}$ is understood from Figure 3. It is perceived that the $\rho_{x}$ rises with $\mathrm{Cr}$ content linearly up to $x=0.2$ and this is because the reduction in the volume of the unit cell increases the density of the sample. Unit cell volume is calculated using the formula $V=a_{0}^{3}$. Unit cell volume is reduced with rising Cr content until $x=0.2$ as it depends on the $a_{0}$ which is also reduced with reducing $\mathrm{Cr}$ content. From the graph, it is perceived that the $\rho_{X}$ is higher than the $\rho_{B}$ one which means that when the samples are sintered, they might contain cracks and pores on the microscopic scale and vacancies in the lattice on the atomic scale [20]. It is observed from Table 1 that the variation of $P$ of the sample behaves exactly in the opposite manner to that of the $\rho_{B}$. The $\rho_{B}$ is diminished with increasing $\mathrm{Cr}^{3+}$ because the atomic mass of $\mathrm{Cr}^{3+}$ is less than that of $\mathrm{Fe}^{3+}$. Moreover, the influence of the residual stress decreases the $\bar{D}$ and increases $P$.

\subsection{Microstructure}

For the morphological study, a microstructural image of $\mathrm{Mn}-\mathrm{Ni}-\mathrm{Zn}-\mathrm{Cr}$ ferrite samples sintered at $1150^{\circ} \mathrm{C}$ was taken using FESEM (Model no. JEOL JSM 7600F) so that an insight of grain structure can be understood. The linear intercept technique was employed to determine the mean grain diameter of the samples.

It is evident from Figure 4 that the $\bar{D}$ is increased with Cr content until $x=$ 0.2 because the doped $\mathrm{Cr}_{2} \mathrm{O}_{3}$ becomes liquid phase in optimized oxygen potential and that liquid phase stimulates the grain growth. The $\bar{D}$ decreases for $x=0.3$ and $x=0.4$ which may be due to the fact that higher compounds can act as obstacles for visco-plastic deformation and $\mathrm{Cr}^{3+}$ resides at the grain boundary and hinders the grain growth. Grain growth and grain boundary mobility are very closely related to each other. Once the homogeneous driving force of grain

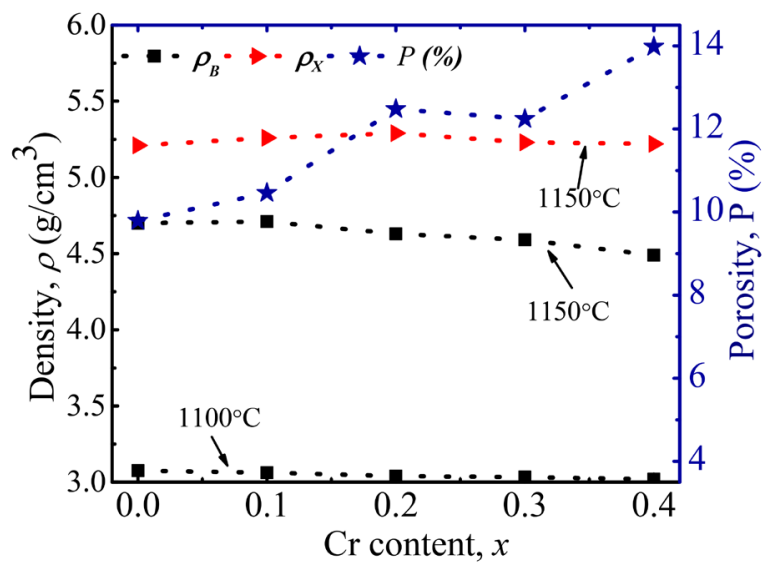

Figure 3. Variation of $\rho_{B}, \rho_{X}$, and $P$ of $\mathrm{Mn}_{0.5} \mathrm{Ni}_{0.1} \mathrm{Zn}_{0.4} \mathrm{Fe}_{2-x} \mathrm{Cr}_{x} \mathrm{O}_{4}$ ferrites as a function of $\mathrm{Cr}$ content. 


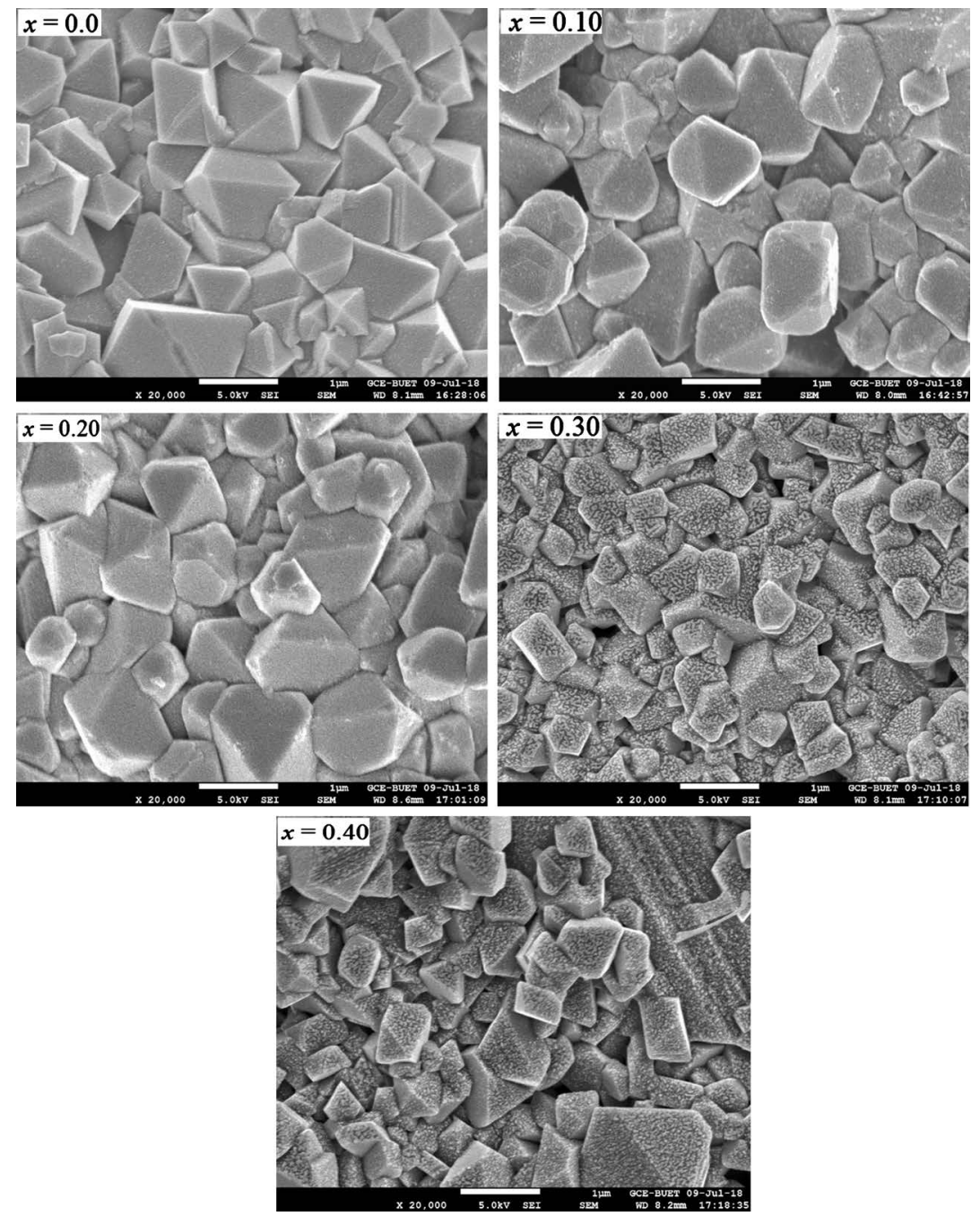

Figure 4. FESEM images of various $\mathrm{Mn}_{0.5} \mathrm{Ni}_{0.1} \mathrm{Zn}_{0.4} \mathrm{Fe}_{2-x} \mathrm{Cr}_{x} \mathrm{O}_{4}$ ferrites.

boundary is attained, the sintered body achieves a unified grain size distribution. The compositional variation of the samples affects the grain size distribution. The grain size reflects the presence of a lesser grain boundary area. The pores are left behind the fast-moving grain boundaries and are confined within the grains only when the grain expansion rate is very high.

\subsection{Magnetic Characterization}

\subsubsection{Complex Initial Permeability}

The $\mu_{i}^{\prime}$ provides a precise description of the stored energy by expressing magnetic induction with the magnetic field. The $\mu_{i}^{\prime}$ has been measured against frequency in the range $10 \mathrm{kHz}-120 \mathrm{MHz}$ at ambient temperature for all the samples of the series $\mathrm{Mn}_{0.5} \mathrm{Ni}_{0.1} \mathrm{Zn}_{0.4} \mathrm{Fe}_{2-x} \mathrm{Cr}_{x} \mathrm{O}_{4}$. From Figure 5, it is noted that with the rise in frequency, the $\mu_{i}^{\prime}$ remains stable up to a particular frequency, and after that $\mu_{i}^{\prime}$ falls rapidly. Generally, the ferri-magnetic order of ferrite develops from anti-parallel and unequal spin moments in the neighboring magnetic sub-lattices which is determined by the distribution of the transition metal 
ions [21]. A substantial amount of $\mathrm{Fe}^{3+}$ ions reside in the octahedral sub-lattice in $\mathrm{Mn}_{0.5} \mathrm{Ni}_{0.1} \mathrm{Zn}_{0.4} \mathrm{Fe}_{2-x} \mathrm{Cr}_{x} \mathrm{O}_{4}$. So, the $\mathrm{Cr}^{3+}$ ion leads the $\mathrm{Fe}^{3+}$ ions to enter into the tetrahedral sub-lattice. Thus the doped sample will show the antiferromagnetic character and the remarkable reduction of $\mu_{i}^{\prime}$ with the rise of $\mathrm{Cr}^{3+}$ results due to this antiferromagnetic behavior of the samples as in Figure 5.

The frequency dependence of the magnetic loss tangent $\left(\tan \delta_{M}\right)$ of the composition $\mathrm{Mn}_{0.5} \mathrm{Ni}_{0.1} \mathrm{Zn}_{0.4} \mathrm{Fe}_{2-x} \mathrm{Cr}_{x} \mathrm{O}_{4}$ sintered at $1150^{\circ} \mathrm{C}$ at ambient temperature over the range $10 \mathrm{kHz}-120 \mathrm{MHz}$ is illustrated in Figure 6. The value of $\tan \delta_{M}$ decreases with frequency arriving at the lowest value and after that becomes nearly constant. The grounds behind reducing $\tan \delta_{M}$ with increasing frequency is that, beyond the definite frequency of the electric field, the domain wall motion cannot go along with the external electric field. It is perceived that the $\tan \delta_{M}$ reduces significantly with the $\mathrm{Cr}$ content at a very high frequency. The low value of the $\tan \delta_{M}$ is the main requirement for the high-frequency magnetic application [16].

The frequency dependence of the RQF of the compositions of $\mathrm{Mn}_{0.5} \mathrm{Ni}_{0.1} \mathrm{Zn}_{0.4}$ $\mathrm{Fe}_{2-x} \mathrm{Cr}_{x} \mathrm{O}_{4}$ sintered at $1150^{\circ} \mathrm{C}$ at ambient temperature over the range $10 \mathrm{kHz}-$ $120 \mathrm{MHz}$ is illustrated in Figure 7. It is perceived that RQF enhances with frequency and after a certain frequency RQF slightly reduces with the rise of frequency.

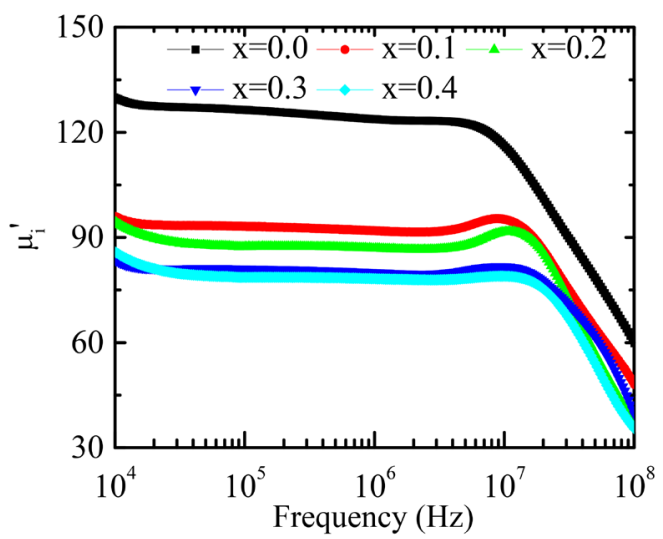

Figure 5. Variation of $\mu_{i}^{\prime}$ of $\mathrm{Mn}_{0.5} \mathrm{Ni}_{0.1} \mathrm{Zn}_{0.4} \mathrm{Fe}_{2-x} \mathrm{Cr}_{x} \mathrm{O}_{4}$ ferrites as a function of frequency.

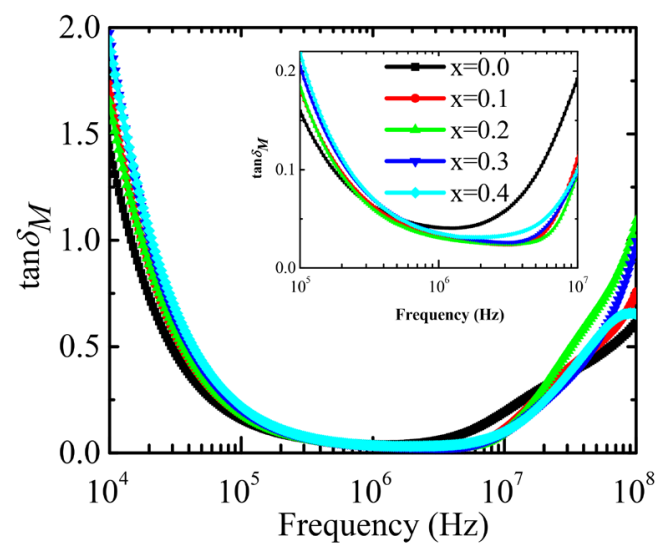

Figure 6. Variation of $\tan \delta_{M}$ of $\mathrm{Mn}_{0.5} \mathrm{Ni}_{0.1} \mathrm{Zn}_{0.4} \mathrm{Fe}_{2-x} \mathrm{Cr}_{x} \mathrm{O}_{4}$ ferrites as a function of frequency. 
RQF has the highest magnitude at a certain frequency where the $\tan \delta_{M}$ has the lowest magnitude [22]. RFQ's improvement can be attributed to the $10 \%$ of $\mathrm{Cr}$ addition and this addition is expected to decrease the $M_{s}$. The RQF is often used as a measure of performance for inductors used in filtering action.

\subsubsection{Temperature-Dependent Complex Initial Permeability}

Curie temperature $\left(T_{c}\right)$ measurement is one of the most significant measurements for magnetic materials. The $T_{c}$ gives substantial information on the magnetic status of a substance for the strength of exchange interaction. The temperature-dependent $\mu_{i}^{\prime}$ for $\mathrm{Mn}_{0.5} \mathrm{Ni}_{0.1} \mathrm{Zn}_{0.4} \mathrm{Fe}_{2-x} \mathrm{Cr}_{x} \mathrm{O}_{4}$ is depicted in Figure 8. The $\mu_{i}^{\prime}$ is measured at a fixed frequency of $100 \mathrm{kHz}$. The $\mu_{i}^{\prime}$ drops rapidly at the temperature when the magnetism of the samples shifts from ferromagnetic to paramagnetic (at Curie point). The sharp fall of $\mu_{i}^{\prime}$ with temperature represents the degree of homogeneity of the samples [23] [24]. In the present case instead of sharp fall $\mu_{i}^{\prime}$ drops rapidly owing to the presence of crack and pores within the samples. It is revealed from Figure 8 that when $\mathrm{Cr}^{3+}$ is doped in $\mathrm{Mn}_{0.5} \mathrm{Ni}_{0.1} \mathrm{Zn}_{0.4} \mathrm{Fe}_{2} \mathrm{O}_{4}, T_{c}$ decreases. The decline in $T_{C}$ is mainly attributable to the weakening of the A-B interaction, which is confirmed from that the ionic radius of $\mathrm{Cr}^{3+}(0.64 \AA)$ is less than $\mathrm{Fe}^{3+}(0.67 \AA)$. Due to the replacement of $\mathrm{Fe}^{3+}$ by $\mathrm{Cr}^{3+}$, the longest distance between moments causes a decrease in A-B interaction in

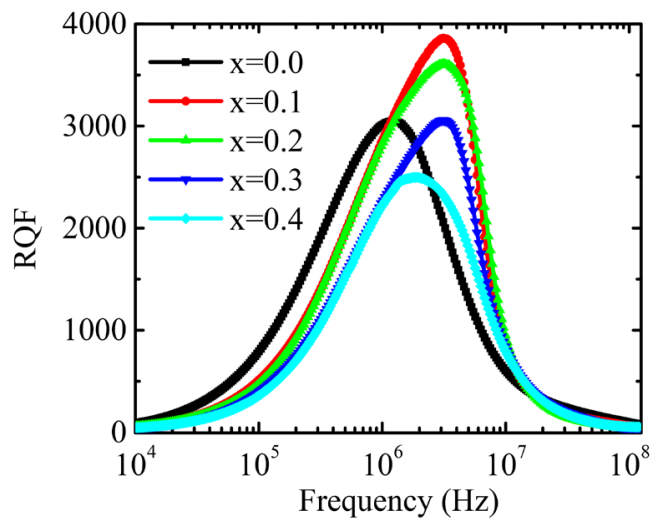

Figure 7. Variation of RQF of $\mathrm{Mn}_{0.5} \mathrm{Ni}_{0.1} \mathrm{Zn}_{0.4} \mathrm{Fe}_{2-x} \mathrm{Cr}_{x} \mathrm{O}_{4}$ ferrites as a function of frequency.

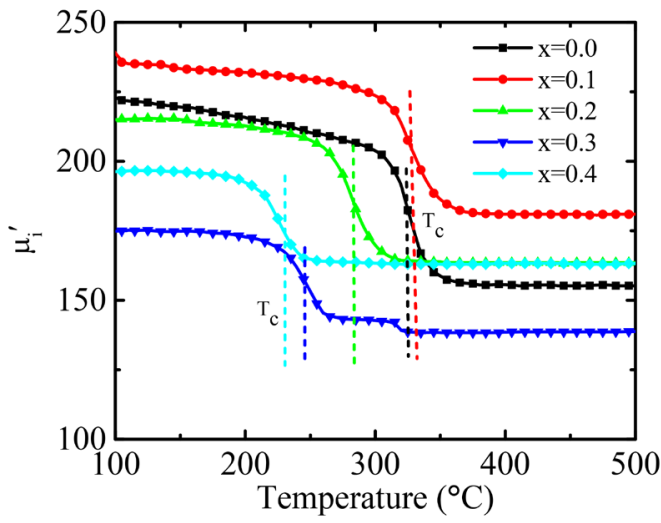

Figure 8. Variation of $\mu_{i}^{\prime}$ with temperature of $\mathrm{Mn}_{0.5} \mathrm{Ni}_{0.1} \mathrm{Zn}_{0.4} \mathrm{Fe}_{2-x} \mathrm{Cr}_{x} \mathrm{O}_{4}$ ferrites. 
the $\mathrm{Mn}_{0.5} \mathrm{Ni}_{0.1} \mathrm{Zn}_{0.4} \mathrm{Fe}_{2} \mathrm{O}_{4}$ relative to all other samples, and consequently, $T_{c}$ decreases [4].

\subsubsection{Magnetic Hysteresis Loop}

Measurement of magnetic hysteresis loop and magnetization for all the samples of $\mathrm{Mn}_{0.5} \mathrm{Ni}_{0.1} \mathrm{Zn}_{0.4} \mathrm{Fe}_{2-x} \mathrm{Cr}_{x} \mathrm{O}_{4}$ were carried out by using Vibrating Sample Magne-

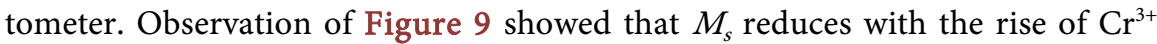
concentration. This happens since the substituted $\mathrm{Cr}^{3+}$ ion has a site preference to occupy B-site which makes the iron enter into the A-site from B-site. As a consequence, the exchange interaction between $\mathrm{A}$ and $\mathrm{B}$ sites turns weaker resulting in intensifying the B-B interaction and weakening the A-B interaction, which in turn reduces the $M_{s}$ of the samples. Besides, $\mathrm{Cr}$ has less magnetic moment than $\mathrm{Fe}$, which may be another reason for the reduction of magnetization with $\mathrm{Cr}$ content. Similar results were reported in other reports [25] [26]. The samples having $x=0.1$ confirmed improved ferromagnetic property as shown in Table 2.

\subsection{Electrical Characterization}

\subsubsection{Dielectric Property}

The variation of frequency-dependent $\varepsilon^{\prime}$ of $\mathrm{Mn}_{0.5} \mathrm{Ni}_{0.1} \mathrm{Zn}_{0.4} \mathrm{Fe}_{2-x} \mathrm{Cr}_{x} \mathrm{O}_{4}$ at ambient temperature is illustrated in Figure 10. It can be realized that the $\varepsilon^{\prime}$ drops rapidly with a rise in frequency thereby showing dispersion in the low-frequency range

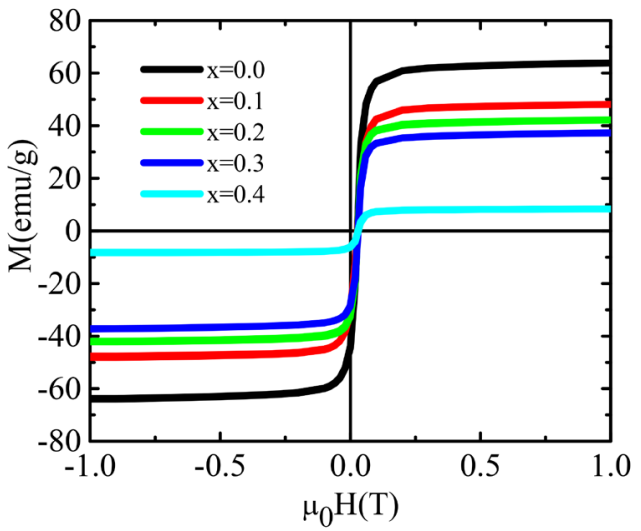

Figure 9. $M$ - $H$ loops of $\mathrm{Mn}_{0.5} \mathrm{Ni}_{0.1} \mathrm{Zn}_{0.4} \mathrm{Fe}_{2-x} \mathrm{Cr}_{x} \mathrm{O}_{4}$ ferrites at room temperature.

Table 2. The $M_{s}$ coercivity $\left(H_{c}\right), K$, remanent magnetization $\left(M_{r}\right)$ of $\mathrm{Mn}_{0.5} \mathrm{Ni}_{0.1} \mathrm{Zn}_{0.4} \mathrm{Fe}_{2-x} \mathrm{Cr}_{x} \mathrm{O}_{4}$ ferrites.

\begin{tabular}{ccccc}
\hline Content, $(\boldsymbol{x})$ & $M_{\boldsymbol{s}}(\mathrm{emu} / \mathrm{g})$ & $H_{c}(\mathrm{~T})$ & $K$ & $M_{\boldsymbol{r}}(\mathrm{emu} / \mathrm{g})$ \\
\hline 0.0 & 61.58 & 2.241 & 69.00 & 0.169 \\
0.1 & 46.31 & 4.367 & 101.118 & 0.213 \\
0.2 & 41.22 & 1.928 & 39.73 & 0.282 \\
0.3 & 36.09 & 2.206 & 39.80 & 0.079 \\
0.4 & 8.31 & 4.697 & 19.52 & 0.071 \\
\hline
\end{tabular}




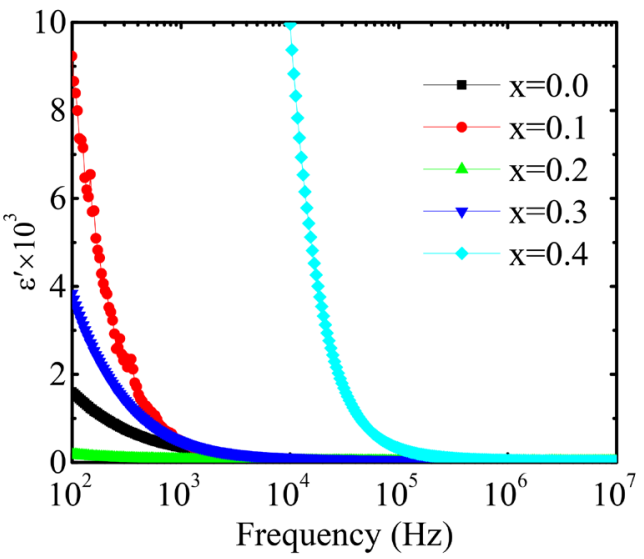

Figure 10. Variation of $\varepsilon^{\prime}$ for various $\mathrm{Mn}_{0.5} \mathrm{Ni}_{0.1} \mathrm{Zn}_{0.4} \mathrm{Fe}_{2-x} \mathrm{Cr}_{x} \mathrm{O}_{4}$ ferrites as a function of frequency.

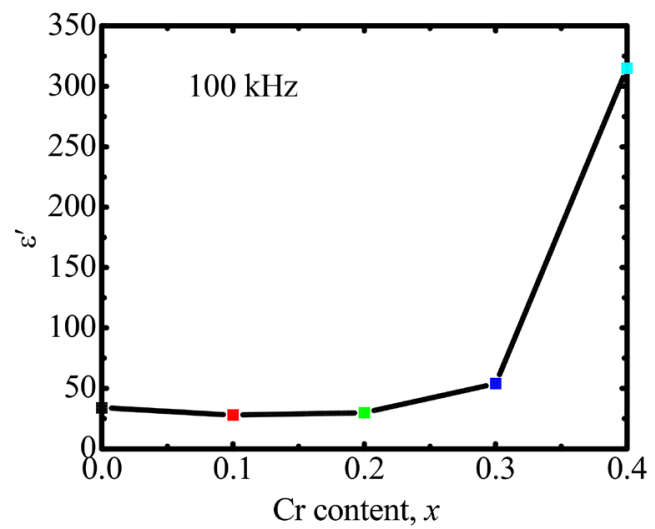

Figure 11. Variation of $\varepsilon^{\prime}$ with Cr content of $\mathrm{Mn}_{0.5} \mathrm{Ni}_{0.1} \mathrm{Zn}_{0.4} \mathrm{Fe}_{2-x} \mathrm{Cr}_{x} \mathrm{O}_{4}$ ferrites.

and become constant at the high-frequency range. The observed dispersion at lower frequencies can be interpreted applying Maxwell-Wagner interfacial polarization which plays a crucial role in such a heterogeneous system [27] [28] [29]. The high values of $\varepsilon^{\prime}$ observed at low-frequency range are because of the presence of the heterogeneity in the composition. Heterogeneities in the samples initiate space charge polarization and contribute towards the high values of $\varepsilon^{\prime}$. As $\mathrm{Cr}$ content rises, the amount of space charge also rises. The reduction of $\mathrm{Fe}^{3+}$ concentration causes the transport of some $\mathrm{Mn}^{2+}$ in the octahedral site which causes an enhancement of hopping charge carriers and consequently provides a high value of $\varepsilon^{\prime}$. Figure 11 displays the variation of $\varepsilon^{\prime}$ with $\mathrm{Cr}$ content at a frequency of $100 \mathrm{kHz}$. The highest $\varepsilon^{\prime}$ is obtained for the sample with $x=0.4$. The grain boundary impedance decreases due to the presence of the second phase in between grains for high $\mathrm{Cr}$ content which in turn increases $\varepsilon^{\prime}$.

The variation of $\tan \delta_{E}$ as a function of the frequency of the composition $\mathrm{Mn}_{0.5} \mathrm{Ni}_{0.1} \mathrm{Zn}_{0.4} \mathrm{Fe}_{2-x} \mathrm{Cr}_{x} \mathrm{O}_{4}$ is shown in Figure 12 sintered at $1150^{\circ} \mathrm{C}$. The $\tan \delta_{E}$ unveils the similar nature of $\varepsilon^{\prime}$. This means that at low frequency the $\tan \delta_{E}$ is high and drops with frequency. The $\tan \delta_{E}$ is proportional to the "loss of energy" from the applied field in the ferrite (in fact this energy is wasted as heat) and 
hence designated as a $\tan \delta_{E}$. The $\tan \delta_{E}$ arises in materials due to the phase difference between polarization and applied field in the high-frequency region.

\subsubsection{AC Resistivity}

The significant electrical property resistivity is an intrinsic property of magnetic material. The resistivity of $\mathrm{Mn}_{0.5} \mathrm{Ni}_{0.1} \mathrm{Zn}_{0.4} \mathrm{Fe}_{2-x} \mathrm{Cr}_{x} \mathrm{O}_{4}$ sintered at $1150^{\circ} \mathrm{C}$ was calculated and plotted against frequency as shown in Figure 13. It is observed that AC resistivity also shows significant dispersion as $\varepsilon$ ' at lower frequencies due to the dominant space charge polarization. At low-frequency AC resistivity rises with $\mathrm{Cr}$ content up to $X=0.2$ and then reduces with a further rise of $\mathrm{Cr}$ content because the $\varepsilon^{\prime}$ is high for samples with higher $\mathrm{Cr}$ concentration i.e., for $x=0.3$ and $x=0.4$. It is found that ac resistivity reduces with frequency showing significant dispersion and this dispersion is more at low-frequency range which might be due to the variation in the concentration of $\mathrm{Fe}^{3+} / \mathrm{Fe}^{2+}$ and other ions in various samples [30].

\subsection{Complex Impedance Spectra Analysis}

Transport properties are strongly dependent on microstructure in polycrystalline solids, and impedance spectra generally include functionalities that may be

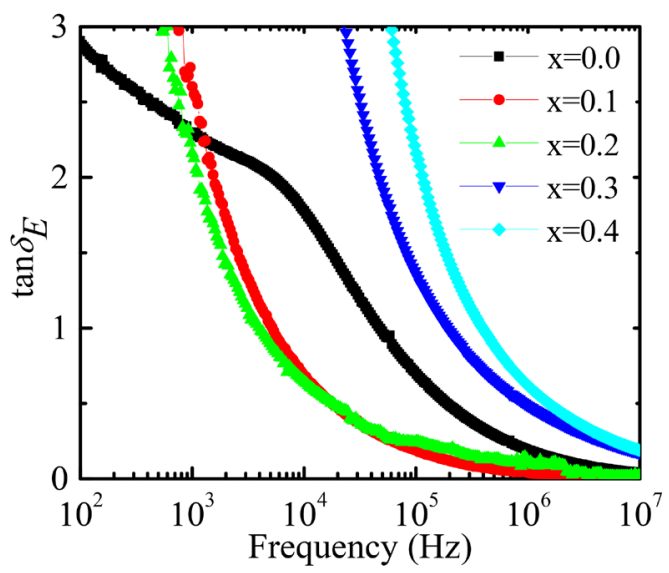

Figure 12. Variation of $\tan \delta_{E}$ of $\mathrm{Mn}_{0.5} \mathrm{Ni}_{0.1} \mathrm{Zn}_{0.4} \mathrm{Fe}_{2-X} \mathrm{Cr}_{X} \mathrm{O}_{4}$ ferrites as a function of frequency.

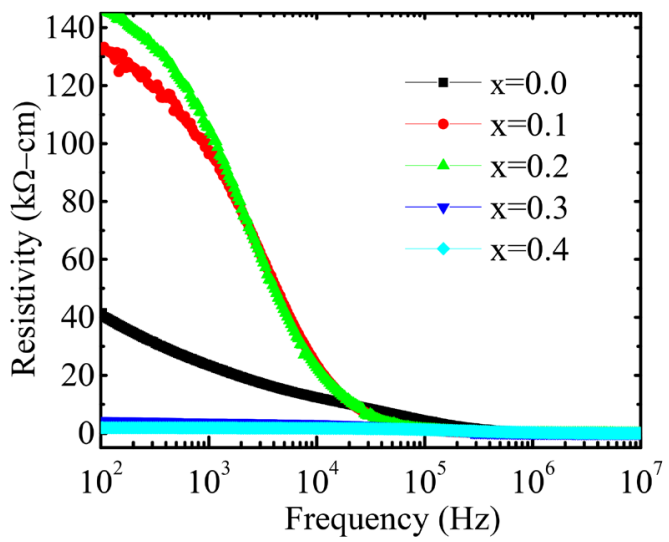

Figure 13. Resistivity of various $\mathrm{Mn}_{0.5} \mathrm{Ni}_{0.1} \mathrm{Zn}_{0.4} \mathrm{Fe}_{2-x} \mathrm{Cr}_{x} \mathrm{O}_{4}$ ferrites as a function of frequency. 
specifically linked to microstructure. Figure 14(a) demonstrates the alteration of resistance $(Z)$ with the frequency of the samples at ambient temperature. The higher value of $Z^{\prime}$ at lower frequency is due to the dominant space charge polarization [31]. Observation confirms that with the rise in frequency up to a specific limit $(\sim 1 \mathrm{kHz})$, the value of $Z^{\prime}$ rapidly decreases which means conductivity of the ferrite samples increases [32]. As all types of polarization are present at the lower frequency it gives higher magnitudes of $Z$ ' But at the high-frequency region, the values of $Z^{\prime}$ decreases as the contribution from different parts of polarization ceases, this is because only electronic polarization can carry over the fast variation of field frequency [33] [34]. The alteration of reactance $\left(Z^{\prime \prime}\right)$ with the frequency is illustrated in Figure 14(b). The frequency dependence of $Z^{\prime \prime}$ [Figure 14(b)] behaves similarly as $Z^{\prime}$ in addition to the appearance of some relaxation peaks due to immobile charges.

According to the brick-layer model, an equivalent circuit comprising of three parallel $R C$ circuits can explain polycrystalline ceramics [35]. Each $R C$ component of the equivalent circuit produces a semicircle in the $Z^{\prime}$ vs $Z^{\prime \prime}$ plot (Cole-Cole diagram). A single semicircle at a higher frequency in $Z^{\prime}$ vs $Z^{\prime \prime}$ plot specifies grain effect, the second semicircle at a lower frequency specifies the presence of grain boundary effect, and a third semicircular arc or spike is often observed which is due to the electrode effect. Figure 15 represents the Cole-Cole plot of various $\mathrm{Mn}_{0.5} \mathrm{Ni}_{0.1} \mathrm{Zn}_{0.4} \mathrm{Fe}_{2-x} \mathrm{Cr}_{x} \mathrm{O}_{4}$ ferrites. It is noticed that the first two compositions ( $x=0.0$ and 0.1 ) show two semicircular arcs one at high frequency for grain interior and another at a lower frequency for grain boundary effect. The rest of the compositions show a single semicircular arc that specifies the materials have only grain contribution to the conduction process as the semicircle appearing at higher frequency correlates to the resistance of grain only but the semicircle at low frequency is because of the resistance of grain boundaries [36]. The grain boundary impedance arises due to the random alignment of grains existing two-dimensional conductivity. The non-existence of grain boundary impedance for $x=0.2,0.3$, and 0.4 may be due to the presence of the second phase dispersed along the grain boundary area which efficiently short
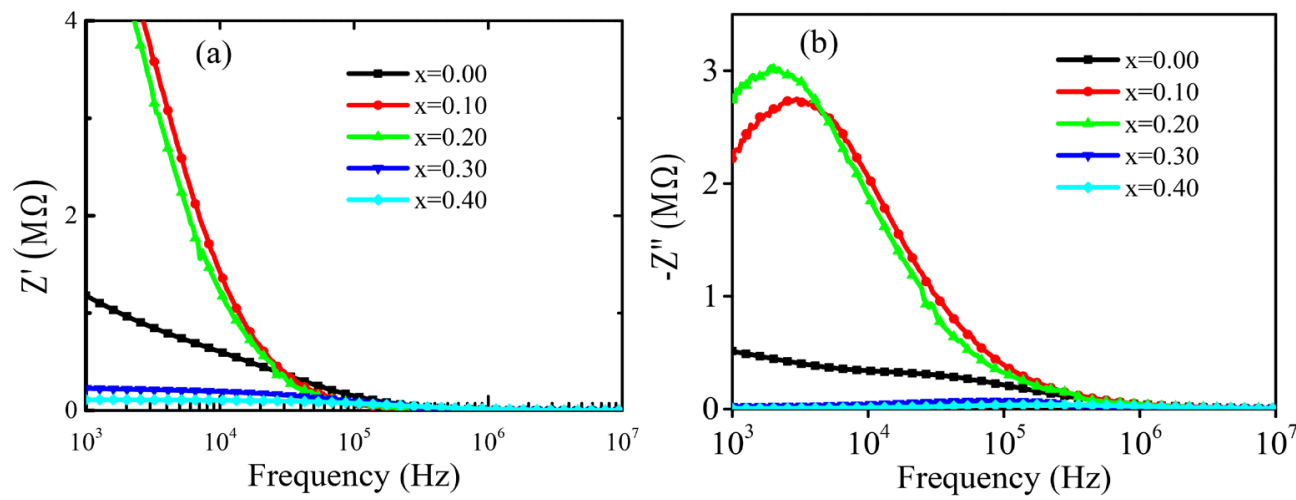

Figure 14. Variation of (a) $Z^{\prime}$ and (b) $Z^{\prime \prime}$ of $\mathrm{Mn}_{0.5} \mathrm{Ni}_{0.1} \mathrm{Zn}_{0.4} \mathrm{Fe}_{2-x} \mathrm{Cr}_{x} \mathrm{O}_{4}$ ferrites as a function of frequency. 

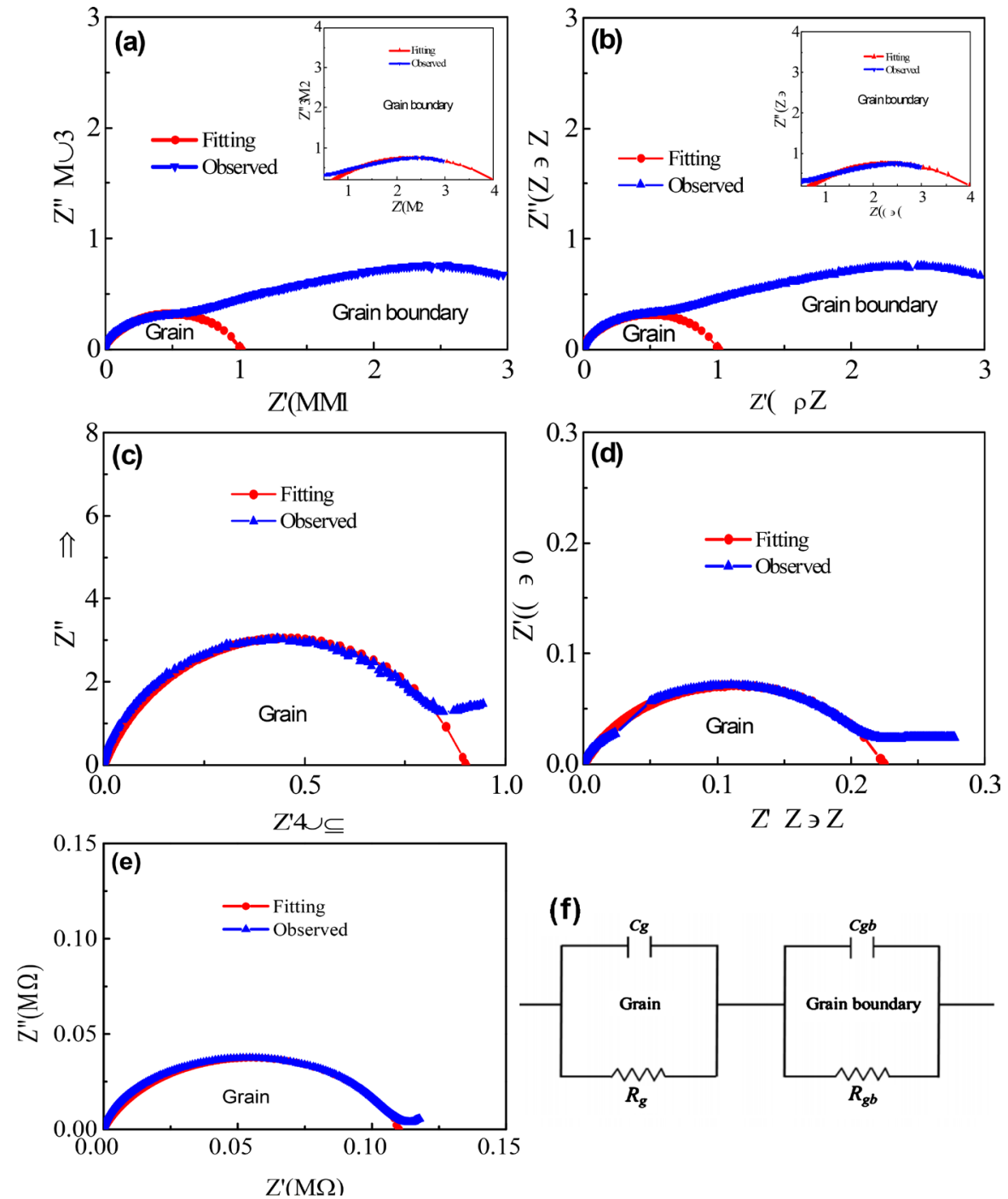

Figure 15. Nyquist plots of different $\mathrm{Mn}_{0.5} \mathrm{Ni}_{0.1} \mathrm{Zn}_{0.4} \mathrm{Fe}_{2-x} \mathrm{Cr}_{x} \mathrm{O}_{4}$ ferrites: (a) $x=0.0$, (b) $x=$ 0.1 , (c) $x=0.2$, (d) $x=0.3$ and (e) $x=0.4$ samples, and (f) equivalent circuit [39].

circuits the grain boundary impedance. Depressed semicircular arcs are perceived for every composition. Experimentally it is unusual to find a complete semicircle with its center lying on the axis of the $Z$. The agitations which result in depressed semicircular arcs in the $Z^{\prime}$ axis are: 1 ) the arcs do not go through the origin because of the presence of other arcs at high frequency and/or the bulk resistance is larger than zero, 2) the centers of the investigational arcs are often relocated below the real axis due to the occurrence of dispersed elements in the material-electrode arrangement [37]. Therefore the relaxation time $(\tau)$ is not single-valued and is spread constantly or separately across a mean $\tau_{m}\left(=\omega_{m}^{-1}\right)$ and 3) arcs might be considerably twisted by additional relaxations. The arcs at higher frequency side constitute bulk resistance and those at the lower frequency side constitute grain boundary resistance [38] [39]. These responses can be explained by an equivalent circuit comprising of two sub-circuits attached in series as depicted in Figure 15(f) [39]. In general, the impedance is expressed as: 
Table 3. The $\varepsilon^{\prime}$, grain, and grain boundary resistances of various $\mathrm{Mn}_{0.5} \mathrm{Ni}_{0.1} \mathrm{Zn}_{0.4} \mathrm{Fe}_{2-x} \mathrm{Cr}_{x} \mathrm{O}_{4}$ ferrites.

\begin{tabular}{cccccc}
\hline Composition & $\boldsymbol{x}=\mathbf{0 . 0}$ & $\boldsymbol{x}=\mathbf{0 . 1}$ & $\boldsymbol{x}=\mathbf{0 . 2}$ & $\boldsymbol{x}=\mathbf{0 . 3}$ & $\boldsymbol{x}=\mathbf{0 . 4}$ \\
\hline$\varepsilon^{\prime}$ at $100 \mathrm{kHz}$ & 35 & 26 & 29 & 55 & 316 \\
$R_{g}(\mathrm{~K} \Omega)$ & 1009 & 1009 & 899 & 224 & 110 \\
$R_{g b}(\mathrm{~K} \Omega)$ & 3267 & 3250 & 0 & 0 & 0 \\
\hline
\end{tabular}

$$
Z^{*}=R_{g}-1 / j w C_{g}+R_{g b}-1 / j w C_{g b}
$$

where $R_{g}$ is the grain resistance, $C_{g}$ is the grain capacitance, $R_{g b}$ is the grain boundary resistance and $C_{g b}$ is the grain boundary capacitance. The arcs in low and high-frequency areas conform to $R_{g b} C_{g b}$ and $R_{g} C_{g}$ responses, respectively. The grain resistance decreases rapidly with the rise in $\mathrm{Cr}^{3+}$ in the composition (Table 3 ) due to the increased space charge polarization.

\section{Conclusion}

The XRD patterns identified a single-phase spinel ferrite structure. The FESEM images revealed that the $\bar{D}$ of the samples increased up to $x=0.2$ owing to the development of $\mathrm{Cr}_{2} \mathrm{O}_{3}$ liquid phase which promoted the grain growth and after $x$ $=0.2, \bar{D}$ decreased due to the shrinkage of the lattice. Among the studied samples, it is clear that $10 \%$ of $\mathrm{Cr}^{3+}$ doped sample has the highest $\varepsilon$ 'with low loss, highest AC resistivity, good magnetizing capability, and highest RQF. The well saturated magnetic hysteresis loop indicated the ferromagnetic character of the present samples. The $T_{C}$ is found to be decreased with $\mathrm{Cr}$ content in the composition resulting from the smaller ionic radius of $\mathrm{Cr}$ than $\mathrm{Fe}$. The impedance spectra analysis established a close correlation of the conduction mechanism with the microstructure of the samples. Both grain and grain boundaries contributed to the total conduction process for the first two compositions. The rest of the compositions had only grain contribution to the conduction process because the second phase dispersed along the grain boundary area efficiently short-circuited the grain boundary impedance. As in the field of electronics and communication devices have to deal with electric as well as magnetic properties, this ferrite composition may be used for the fabrication of different electronic and communication devices.

\section{Acknowledgements}

The authors are thankful to the Dept. of Physics, Comilla University, Cumilla; Atomic Energy Centre, Dhaka (AECD), and Ministry of Science and Technology, Government of the People's Republic of Bangladesh.

\section{Conflicts of Interest}

The authors declare no conflicts of interest regarding the publication of this paper. 


\section{References}

[1] Sivakumar, N., Narayanasamy, A., Ponpandian, N. and Govindaraj, G. (2007) Grain Size Effect on the Dielectric Behavior of Nanostructured $\mathrm{Ni}_{0.5} \mathrm{Zn}_{0.5} \mathrm{Fe}_{2} \mathrm{O}_{4}$. Journal of Applied Physics, 101, 084116. https://doi.org/10.1063/1.2721379

[2] Hossain, A.K.M.A., Mahmud, S.T., Seki, M., Kawai, T. and Tabata, H. (2007) Structural, Electrical Transport, and Magnetic Properties of $\mathrm{Ni}_{1-\mathrm{x}} \mathrm{Zn}_{\mathrm{x}} \mathrm{Fe}_{2} \mathrm{O}_{4}$. Journal of Magnetism and Magnetic Materials, 312, 210-219. https://doi.org/10.1016/j.jmmm.2006.09.030

[3] Goldman, A. (1999) Handbook of Modern Ferromagnetic Materials. Kulwer Academic Publishers, Boston. https://doi.org/10.1007/978-1-4615-4917-8

[4] Valenzuela, R. (1994) Magnetic Ceramics. Cambridge University Press, Cambridge. https://doi.org/10.1017/CBO9780511600296

[5] Chukalkin, Y.G. and Teplykh, A.E. (1998) Magnetic State of Nickel-Zinc Ferrites at High Zinc Concentrations. Physics of the Solid State, 40, 1364-1365. https://doi.org/10.1134/1.1130559

[6] Mahmud, S.T., Akther Hossain, A.K.M., Abdul Hakim, A.K.M., Seki, M., Kawai, T. and Tabata, H. (2006) Influence of Microstructure on the Complex Permeability of Spinel Type Ni-Zn Ferrite. Journal of Magnetism and Magnetic Materials, 305, 269-274. https://doi.org/10.1016/j.jmmm.2006.01.012

[7] Rezlescu, N., Rezlescu, E., Pasnicu, C. and Craus, M.L. (1994) Effects of the Rare-Earth Ions on Some Properties of a Nickel-Zinc Ferrite. Journal of Physics. Condensed Matter, 6, 5707-5716. https://doi.org/10.1088/0953-8984/6/29/013

[8] Rezlescu, E., Sachelarie, L., Popa, P.D. and Rezlescu, N. (2000) Effect of Substitution of Divalent Ions on the Electrical and Magnetic Properties of Ni-Zn-Me Ferrites. IEEE Transactions on Magnetics, 36, 3962-3967.

https://doi.org/10.1109/20.914348

[9] Singh, A.K., Goel, T.C., Mendiratta, R.G., Thakur, O.P. and Prakash, C. (2002) Magnetic Properties of Mn-Substituted Ni-Zn Ferrites. Journal of Applied Physics, 92, 3872-3876. https://doi.org/10.1063/1.1504493

[10] Singh, A.K., Goel, T.C. and Mendiratta, R.G. (2004) Low-Temperature Synthesis of $\mathrm{Mn}_{0.2} \mathrm{Ni}_{0.2} \mathrm{Zn}_{0.6} \mathrm{Fe}_{2} \mathrm{O}_{4}$ Ferrites by Citrate Precursor Method and Study of Their Properties. Physica Status Solidi (a), 201, 1453-1457.

https://doi.org/10.1002/pssa.200306775

[11] Singh, A.K., Goel, T.C. and Mendiratta, R.G. (2003) Effect of Manganese Impurity on the Conductivity, Dielectric Behavior and Magnetic Properties of $\mathrm{Ni}_{0.3} \mathrm{Mn}_{\mathrm{x}} \mathrm{Zn}_{0.7-\mathrm{x}}$ $\mathrm{Fe}_{2} \mathrm{O}_{4}$. Japanese Journal of Applied Physics, 42, 2690-2691.

https://doi.org/10.1143/JJAP.42.2690

[12] Sattar, A.A., El-Sayed, H.M., El-Shokrofy, K.M. and El-Tabey, M.M. (2005) Improvement of the Magnetic Properties of Mn-Ni-Zn Ferrite by the Non Magnetic Al-Ion Substitution. Journal of Applied Science, 5, 162.

[13] Sattar, A.A., El-Sayed, H.M., El-Shokrofy, K.M. and El-Tabey, M.M. (2005) Effect of Manganese Substitution on the Magnetic Properties of Nickel-Zinc Ferrite. Journal of Materials Engineering and Performance, 14, 99-103. https://doi.org/10.1361/10599490522185

[14] Kulkarni Suresh, R. (2012) Development of In $^{3+}$ Substituted Mn-Ni-Zn Nanoferrite Core Material. Archives of Physics Research, 3, 116.

[15] Eltabey, M.M., Agami, W.R. and Mohsen, H.T. (2014) Improvement of the Magnetic Properties for Mn-Ni-Zn Ferrites by Rare Earth $\mathrm{Nd}^{3+}$ Ion Substitution. Journal 
of Advanced Research, 5, 601-605. https://doi.org/10.1016/j.jare.2013.08.005

[16] Cullity, B.D. (1972) Introduction to Magnetic Materials. Addison-Wisley Publishing Company, Inc., Menlo Park.

[17] Mane, D.R., Birajdar, D.D., Shirsath, S.E., Telugu, R.A. and Kadam, R.H. (2010) Structural and Magnetic Characterizations of Mn-Ni-Zn Ferrite Nanoparticles. Physica Status Solidi (a), 207, 2355-2363. https://doi.org/10.1002/pssa.201026079

[18] Vegard, L. (1921) Die Konstitution der Mischkristalle und die Raumfüllung der Atome. Zeitschrift für Physik, 5, 17-26. https://doi.org/10.1007/BF01349680

[19] Li, Z., Dai, J., Cheng, C., Suo, Z. and Qing, W. (2020) Synthesis and Magnetic Properties of Chromium Doped Cobalt Ferrite Nanotubes. Materials Research Express, 7, 086102. https://doi.org/10.1088/2053-1591/abae26

[20] Cullity, B.D. and Stock, S.R. (2001) Elements of X-Ray Diffraction. 3rd Edition, Prentice Hall, Upper Saddle River.

[21] Xu, F., Bai, Y., Ai, F. and Qiao, L.J. (2008) The Magnetic and Dielectric Properties of Multiferroic Sr-Substituted $\mathrm{Zn}_{2}-\mathrm{Y}$ Hexagonal Ferrites. Chinese Physics B, 17, 4652-4655. https://doi.org/10.1088/1674-1056/17/12/054

[22] Overshott, K. (1981) The Causes of the Anomalous Loss in Amorphous Ribbon Materials. IEEE Transactions on Magnetics, 17, 2698-2700.

https://doi.org/10.1109/TMAG.1981.1061648

[23] Cedillo, E., Ocampo, J., Rivera, V. and Valenzuela, R. (1980) An Apparatus for the Measurement of Initial Magnetic Permeability as a Function of Temperature. Journal of Physics E: Scientific Instruments, 13, 383-386.

https://doi.org/10.1088/0022-3735/13/4/005

[24] Valenzuela, R. (1980) A Sensitive Method for the Determination of the Curie Temperature in Ferrimagnets. Journal of Materials Science, 15, 3173-3174. https://doi.org/10.1007/BF00550394

[25] Alam, F., Rahman, M.L., Khan, M.H.R. and Hossain, A.K.M.A. (2014) Magnetic Hysteresis and Complex Initial Permeability of $\mathrm{Cr}^{3+}$ Substituted Mn-Zn Ferrites. Journal of Modern Physics, 5, 1223-1233. https://doi.org/10.4236/jmp.2014.514122

[26] Guilland, C. and Creveaux, H. (1950) Comptes Rendus de P Académie des Sciences, 230, 1256.

[27] Mazumdar, S.C., Khan, M.N.I., Islam, M.F. and Hossain, A.K.M.A. (2015) Enhanced Multiferroic Properties in (1-y) $\mathrm{BiFeO}_{3-\mathrm{y}} \mathrm{Ni}_{0.50} \mathrm{Cu}_{0.05} \mathrm{Zn}_{0.45} \mathrm{Fe}_{2} \mathrm{O}_{4}$ Composites. Journal of Magnetism and Magnetic Materials, 390, 61-69. https://doi.org/10.1016/j.jmmm.2015.04.087

[28] Maxwell, J.C. (1973) Electricity and Magnetism. Oxford University Press, London.

[29] Chougule, S.S. and Chougule, B.K. (2008) Response of Dielectric Behavior and Magnetoelectric Effect in Ferroelectric Rich (x) $\mathrm{Ni}_{0.9} \mathrm{Zn}_{0.1} \mathrm{Fe}_{2} \mathrm{O}_{4}+(1-\mathrm{x}) \mathrm{PZT}$ ME Composites. Journal of Alloys and Compounds, 456, 441-446. https://doi.org/10.1016/j.jallcom.2007.02.089

[30] Yang, H., Wang, H., He, L., Shui, L. and Yao, X. (2010) Polarization Relaxation Mechanism of $\mathrm{Ba}_{0.6} \mathrm{Sr}_{0.4} \mathrm{TiO}_{3} / \mathrm{Ni}_{0.8} \mathrm{Zn}_{0.2} \mathrm{Fe}_{2} \mathrm{O}_{4}$ Composite with Giant Dielectric Constant and High Permeability. Journal of Applied Physics, 108, 074105. https://doi.org/10.1063/1.3490782

[31] Dhak, P., Dhak, D., Das, M., Pramanik, K. and Pramanik, P. (2009) Impedance Spectroscopy Study of $\mathrm{LaMnO}_{3}$ Modified $\mathrm{BaTiO}_{3}$ Ceramics. Materials Science and Engineering: B, 164, 165-171. https://doi.org/10.1016/j.mseb.2009.09.011 
[32] Brahma, S., Choudhary, R.N.P. and Thakur, A.K. (2005) AC Impedance Analysis of LaLiMo $_{2} \mathrm{O}_{8}$ Electroceramics. Physica B: Condensed Matter, 355, 188-201. https://doi.org/10.1016/j.physb.2004.10.091

[33] Behera, B., Nayak, P. and Choudhary, R. (2008) Structural and Electrical B. Behera, P. Nayak, R.N.P. Choudhary, Structural and Electrical Properties of $\mathrm{KCa}_{2} \mathrm{Nb}_{5} \mathrm{O}_{15}$ Ceramics. Central European Journal of Physics, 6, 289-295. https://doi.org/10.2478/s11534-008-0030-4

[34] Intatha, U., Eitssayeam, S., Wang, J. and Tunkasiri, T. (2010) Impedance Study of Giant Dielectric Permittivity in $\mathrm{BaFe}_{0.5} \mathrm{Nb}_{0.5} \mathrm{O}_{3}$ Perovskite Ceramic. Current Applied Physics, 10, 21-25. https://doi.org/10.1016/j.cap.2009.04.006

[35] MacDonald, J.R. (1987) Impedance Spectroscopy. Wiley-Interscience, New York.

[36] Behera, C., Choudhary, R.N.P. and Das, P.R. (2016) Structural, Dielectric, Impedance and Magneto-Electric Properties of Mechanically Synthesized $\left(\mathrm{Bi}_{0.5} \mathrm{Ba}_{0.25} \mathrm{Sr}_{0.25}\right)$ $\left(\mathrm{Fe}_{0.5} \mathrm{Ti}_{0.5}\right) \mathrm{O}_{3}$ Nano-Electronic System. Materials Research Express, 3, 035005. https://doi.org/10.1088/2053-1591/3/3/035005

[37] Barsoukov, E. and Macdonald, J.R. (2005) Impedance Spectroscopy: Theory, Experiment, and Applications. John Wiley \& Sons, Inc., Hoboken.

https://doi.org/10.1002/0471716243

[38] Das, M.K., Zubair, M.A., Tanaka, H. and Hossain, A.K.M.A. (2020) Study of Impedance and Magnetoelectric Property of Lead-Free xLCNZFO+(1-x)BGTDO Multiferroic Composites. Materials Chemistry and Physics, 255, 123575.

https://doi.org/10.1016/j.matchemphys.2020.123575

[39] Mazumdar, S.C., Khan, M.N.I., Islam, M.F. and Hossain, A.K.M.A. (2016) Tuning of Magnetoelectric Coupling in (1-y) $\mathrm{Bi}_{0.8} \mathrm{Dy}_{0.2} \mathrm{FeO}_{3}-\mathrm{yNi}_{0.5} \mathrm{Zn}_{0.5} \mathrm{Fe}_{2} \mathrm{O}_{4}$ Multiferroic Composites. Journal of Magnetism and Magnetic Materials, 401, 443-454. https://doi.org/10.1016/j.jmmm.2015.10.051 